\title{
Behavior of unsaturated pelitic soil in a railway context
}

\author{
Bilal Yoka Khail, ${ }^{1 *}$, Mathilde Morvan ${ }^{1}$, and Pierre Breul ${ }^{1}$ \\ ${ }^{1}$ Institut Pascal, Polytech Clermont-Ferrand, Université Clermont Auvergne, Clermont-Ferrand, France
}

\begin{abstract}
As part of the rehabilitation work on the Gabonese railway line, the Trans-Gabon Railway, it was necessary to analyse the behaviour of the materials constituting the subgrade soil. These soils are pelitic soils whose behaviour under unsaturated conditions and cyclic loading has not been studied before and which present differential settlements and lack of bearing capacity. In this article, we focus on the characterization of the subgrade soil. The objective of this work is first to determine the in-situ characteristics of the pelitic soil and be able to link these characteristics with the behaviour studied in laboratory. For that purpose, we propose an in-situ investigation based on the use of light dynamic penetrometric tests in order to assess the variability of the subgrade layer and a drying-wetting test to assess the influence of hydric stress on the drainage path of the studied soil. We present the results of in-situ tests performed on a study area. We also present the results of the tests to determine the soil water characteristic curves (SWCC) and the curves describing the volumetric behaviour of this soil when exposed to drying.
\end{abstract}

\section{Introduction}

In recent years, the needs for rail transport has become increasingly important due to an ever-increasing number of people and products to transport. This leads to a diversification and expansion of rail networks. Many authors have demonstrated that increasing axle loads and train speeds have a negative effect on the performance of ballasted railways, both on the superstructure and on the trackbed [1-5].

With cyclic loading in undrained condition, subgrade soil with fine-grained soil exhibits some problems with the combination of many factors such as loading, soil moisture and soil temperature [1,2]. Repeated loading is known to have a significant effect on the cumulative plastic strains of the subgrade soil and in the reduction of its strength $[1,2,4]$. [5] noted that suction is an important parameter that governs the mechanical behaviour of pavement subgrade; increasing soil suction results in an increase in soil stiffness and high resilient modulus. The effects of soil suction were also studied by [4] who found that higher initial matric suction induces larger deviator stress and smaller failure strain for unsaturated clayey soil on their monotonic and post-cyclic behaviour. So, the study of these factors and their effects on the mechanical behaviour of the soils constituting the railway subgrades is of interest.

Railway subgrade with pelitic soil, which is finegrained soil, can present some problems, such as differential settlements and lack of bearing capacity, due to the degradation of these mechanical properties with high cyclic loading and poor drainage conditions. A good understanding of the mechanical behaviour of this subgrade soil depends on complementary laboratory and in-situ studies.
In this paper, we focus on the behaviour in characterization of the subgrade soil in a part of the Trans-Gabon Railway line. The railway subgrade of this part of the track consists of a residual pelitic soil. This soil is subject to important water content variations (dry season and rain season) and to heavy cyclic loading which can lead to the degradation of its mechanical properties.

The knowledge of its behaviour in different saturation conditions is a major issue. For that purpose, a methodology to assess the geotechnical characterization of this railway subgrade layer has been implemented [6]. The aim of this paper is firstly to define the extent of the subgrade soil, to estimate its in-situ resistance and to assess the variability of these mechanical properties and secondly to identify some unsaturated properties of this pelitic soil, especially the study of the hydro-mechanical behaviour toward soil water retention curves and of the volumetric variations due to drying. Finally, we propose relationship in order to relate unsaturated properties to the characteristics measured in-situ.

\section{Pelitic soil}

From geological point of view, pelite is a mudstone; it is a fine-grained clayey rock belonging to the family of clastic sediments, which represents more than $65 \%$ of the sediments. It is a rock rich with clay and silt particles [7]. The material we are studying is therefore a residual pelitic soil (or weathered clay) resulting from the in-situ weathering of a clayey-silty parent rock present on the cocobeach formation lands located in the interior basin of Gabon.

Residual soils have been studied by several authors

Corresponding author: yokabilal92@gmail.com 
such as Fookes et al. (1971), Fookes (1997), Little (1969), Anon (1981) (quoted in [8]). They have produced a typical profile of residual soils that is perceived as a morphological description based on the different grades of weathering from fresh rock to residual soil. The degree of alteration is increasing from the parent rock to the residual soil at the surface (Table 1). The physico-chemical and mechanical properties of residual pelitic soils generally result from their degree of weathering, geological history (stress history), lithology and the type of test applied to study them [7].

These soils are characterized by low permeability, low shear strength (especially when wet) and are often associated with landslide problems [9].

Table 1. weathering grade [7].

\begin{tabular}{|c|c|c|}
\hline Term & Grade & Description \\
\hline Fresh & IA & No visible sign of weathering \\
\hline $\begin{array}{c}\text { Faintly } \\
\text { weathered }\end{array}$ & IB & $\begin{array}{c}\text { Discolouration on major } \\
\text { discontinuity surfaces. }\end{array}$ \\
\hline $\begin{array}{c}\text { Slighlty } \\
\text { weathered }\end{array}$ & II & Discolouration \\
\hline $\begin{array}{c}\text { Moderatly } \\
\text { weathered }\end{array}$ & III & $\begin{array}{c}\text { Less than half of rock material } \\
\text { decomposed. }\end{array}$ \\
\hline $\begin{array}{c}\text { Highly } \\
\text { weathered }\end{array}$ & IV & $\begin{array}{c}\text { More than half of rock material } \\
\text { decomposed. }\end{array}$ \\
\hline $\begin{array}{c}\text { Completly } \\
\text { weathered }\end{array}$ & V & $\begin{array}{c}\text { All rock material decomposed; } \\
\text { original mass structure still } \\
\text { largely intact. }\end{array}$ \\
\hline $\begin{array}{c}\text { Residual } \\
\text { soil }\end{array}$ & VI & $\begin{array}{c}\text { All rock material converted to } \\
\text { soil. Mass structure and material } \\
\text { fabric are destroyed. }\end{array}$ \\
\hline
\end{tabular}

\section{In-situ investigation}

\subsection{Site location}

The site studied is a part of the Trans-Gabon Railway line located in Gabon, in Central Africa. This part of the track is included in a cut section located approximatively at $57 \mathrm{~km}$ from Libreville (Figure 1) and has problems of differential settlements and bearing capacity. From a geological point of view, this area is located on land formed in the lower cretaceous age (neocamian to barremian). The average height of the cut section is approximatively $2.5 \mathrm{~m}$ and the track is in straight line alignement with an approximate width of $6 \mathrm{~m}$. In this section, the railway crosses the equatorial forest and passes near many watercourses. The structure is equipped with lateral earth ditches in which there is often ponding water even in the dry season.

The studied area is located in the northwestern region of the country where the annual recorded rainfall is about $3000 \mathrm{~mm}$. The trains taking this track are loaded at $25 \mathrm{t}$ per axle.

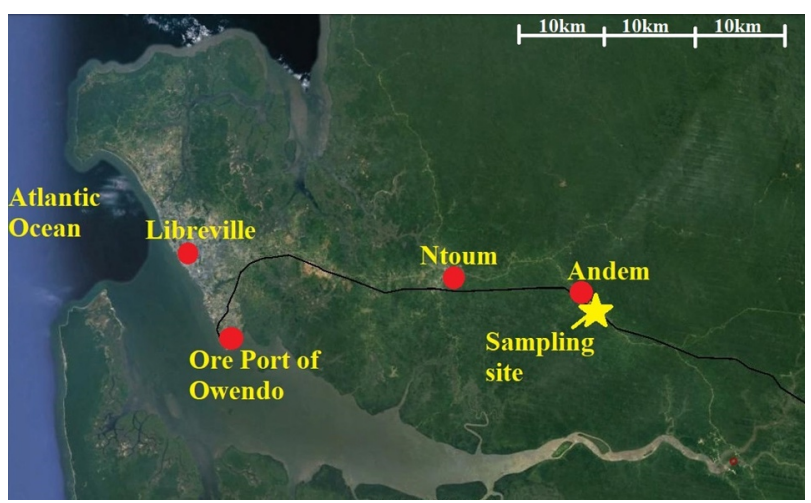

Fig.1. Location of the site studied.

\subsection{Geotechnical investigations}

We conducted a series of PANDA penetrometric tests coupled with geoendoscopic tests to assess the variability of the in-situ resistance of the subgrade soil and to identify the structural layers of the rail track [6].

The PANDA test [6] is a light dynamic penetrometric test that consists in driving a set of rods into the ground with a tip at its extremity. The drilling is done by manual beating using a standard hammer. For each blow, the beating energy supplied and the displacement of the rod are automatically recorded.

The geoendoscopic test [6] consists in driving an endoscopic camera into the borehole previously drilled with the PANDA test to record images of the soil being examined. The images are taken automatically and a video of the survey is also taken in parallel. Each image taken is associated with a depth. The various images obtained will be used for image processing and analysis for an assessment of the conditions and nature of the soil.

A total of ten penetrometric and two geoendoscopic boreholes were drilled on the track portion studied. The penetrometric drillings were spaced so as to cover the entire study area. A maximum auscultation depth of $3 \mathrm{~m}$ was chosen to be able to cover a large part of the subgrade. The drillings were conducted from the top of the ballast layer. An illustration of a portion of the track is given in Figure 2.

During this campaign of in-situ tests, soils samples were also collected in a well with $1.7 \mathrm{~m}$ deep from the earthworks levelling, and located at about $2.4 \mathrm{~m}$ from the track, to take soil samples for laboratory tests.

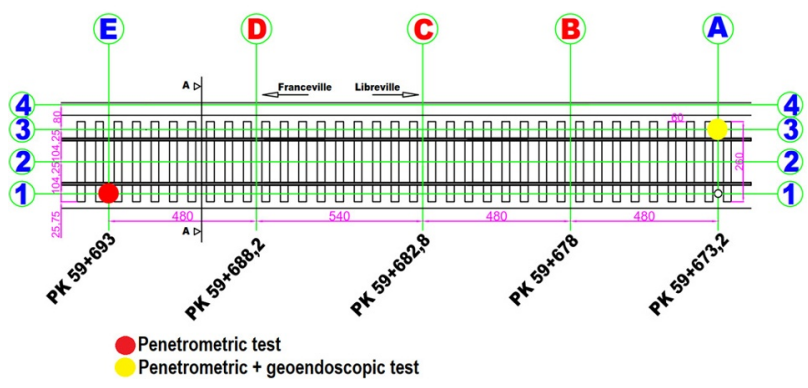

Fig. 2. Illustration of a section of track with borehole distribution for in-situ testing. 


\subsection{Results of in-situ tests}

The railway structure on the studied area has been deduced from the PANDA and geoendoscopy tests coupling. From top to bottom, we found: a ballast layer, a transition layer and the subgrade. It can be seen that the residual pelitic soil constituting the subgrade corresponds to a soft clay. An example of a PANDA/geoendoscope tests coupling is given in Figure 3 , and depending on the results obtained, the subgrade can be classified as a class $S O$ material, according to the adaptation of the French railway subgrade classification made by [6]. The class material $S O$ corresponds to soils with a soft consistency and dynamic cone resistances lower than 10MPa.

It can also be seen that the pelitic soil constituting the subgrade is in a high hydric state. These tests were carried out during the short dry season, which is a period of rainy recession in Gabon.

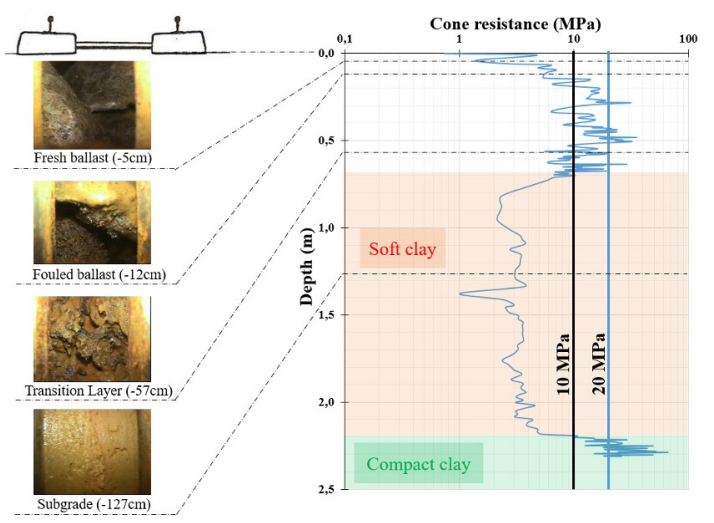

Fig. 3. PANDA/geoendoscope coupling test results.

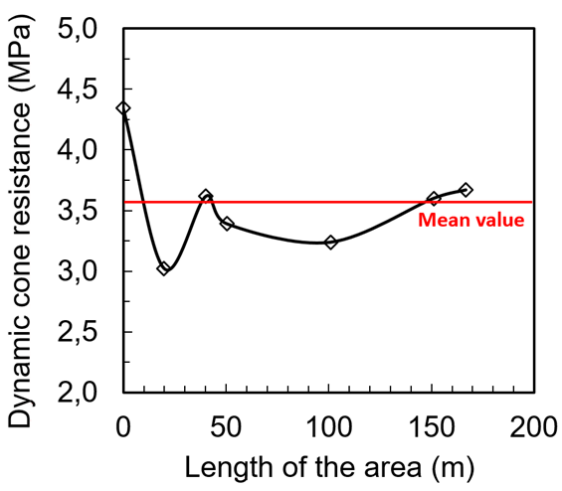

Fig. 4. Variation of the mean dynamic cone resistance in the PST on the total length of the studied area (only seven measurements are represented because three of the ten measurements were cancelled).

Figure 4 shows the variation of the mean dynamic cone resistance on the top part of the earthworks (PST) over the total length of the study area. The PST corresponds to the surface part of the subgrade taken over a thickness of about $1 \mathrm{~m}$. It can be seen that the dynamic cone resistance varies slightly on the total linear of the area in the PST; it remains at a mean value about 3.6MPa. These results are summarized in Table 2 and it can be concluded that the pelitic soil constituting the subgrade is rather homogeneous.

Figure 5 shows the fit of the dynamic cone resistance distribution by a normal distribution for all values of dynamic cone resistance in the PST.

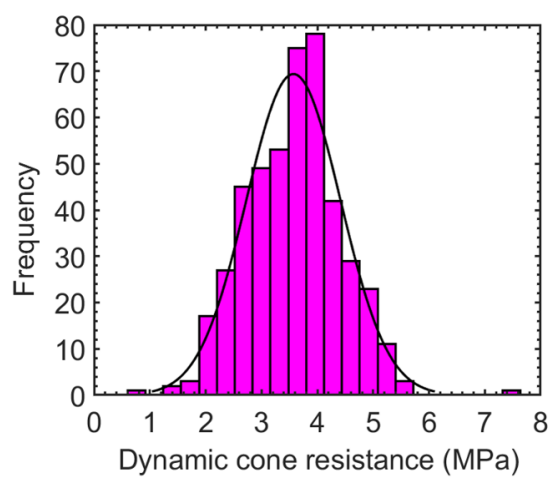

Fig. 5. Fitting of the dynamic cone resistance distribution by a normal distribution for the PST.

Table 2. Thickness and cone resistance in subgrade soil.

\begin{tabular}{ccc}
\hline & $\begin{array}{c}\text { Thickness } \\
(\mathrm{cm})\end{array}$ & $\begin{array}{c}\text { Dynamic cone } \\
\text { resistance } \\
(\mathrm{MPa})\end{array}$ \\
\hline Mean & 100.6 & 3.6 \\
Max & 101.9 & 7.6 \\
Min & 100.2 & 0.8 \\
Standard & 0.56 & 0.85 \\
deviation & & \\
\hline
\end{tabular}

The low variability of the mean cone resistance in the subgrade soil show the homogeneity of this layer and the influence of the hydric state on the resistance values. This is why, to accompany this in-situ characterization, we conducted laboratory tests that consist of determining SWCC and the curves giving the drying-wetting paths to get an overview of the hydro-mechanical behaviour of this soil.

\section{Laboratory studies}

Various laboratory tests (i.e. SWCC and shrinkage test) have been performed on the samples collected in field (see 3.2). Table 3 presents the results obtain according to the French soil classification GTR 92 (NF P 11 300).

Table 3. Physical and geotechnical properties of the soil studied

\begin{tabular}{|c|c|}
\hline GTR class & A3th \\
\hline Liquid limit $\left(W_{L}\right)$ & $78.93 \%$ \\
\hline Plastic limit $\left(W_{P}\right)$ & $40.42 \%$ \\
\hline Plasticity index $\left(I_{P}\right)$ & $38.51 \%$ \\
\hline Finer percent $(\% 80 \mu m)$ & $92.65 \%$ \\
\hline Maximum particles size $\left(D_{\max }\right)$ & $12.5 \mathrm{~mm}$ \\
\hline Organic matter content $(M O)$ & $8.30 \%$ \\
\hline Natural water content $\left(w_{\text {nat }}\right)$ & $46.24 \%$ \\
\hline $\begin{array}{c}\text { Optimum modified Proctor moisture } \\
\text { content }\end{array}$ & $19.97 \%$ \\
\hline $\begin{array}{c}\text { Maximum modified Proctor dry } \\
\text { density }\end{array}$ & $16.50 \mathrm{kN} / \mathrm{m}^{3}$ \\
\hline Volumetric mass of solid particles $\left(\rho_{s}\right)$ & $26.95 \mathrm{kN} / \mathrm{m}^{3}$ \\
\hline
\end{tabular}




\subsection{Soil Water Characteristic Curves (SWCC)}

We determined four SWCCs for different dry densities (i.e. $15.7 \mathrm{kN} / \mathrm{m}^{3}, 14.3 \mathrm{kN} / \mathrm{m}^{3}, 1.32 \mathrm{kN} / \mathrm{m}^{3}$ and $12.4 \mathrm{kN} / \mathrm{m}^{3}$ that correspond in terms of percentage of Maximum Modified Proctor Dry Density (MMPD) to 95\%, 87\%, $80 \%$ and $75 \%$ respectively) to evaluate the influence of this parameter on SWCC. The curves for $87 \%$ and $75 \%$ of the MMPD correspond respectively to the in-situ densities at $70 \mathrm{~cm}$ and $120 \mathrm{~cm}$ depth in the subgrade, from the levelling of the earthworks. We note that the dry density at $70 \mathrm{~cm}$ depth is greater than that at $120 \mathrm{~cm}$ depth due to track compaction work of the upper part of the earthworks.

For this test, we use the filter paper method which is commonly used in geotechnical engineering to determine soil suction $[10,11,12]$. It was accepted as a standard method for soil suction measurement by the American Society for Testing Material (ASTM) standard ASTM D5298 in 2003 [10].

The test to determine the SWCCs curves consists in placing three filter papers between two soil samples for a period of time to ensure that the balance between the matrix suction of the soil and the central filter paper is achieved. For our tests, we waited four weeks to reach balance. We then determined the water content of the central filter paper and that of the soil. The calibration curve of Whatman filter paper No.42 allows the matrix suction $(\psi)$ of filter paper to be determined as a function of its water content $(w)$ as presented by equations (1) and (2) [13]. At equilibrium, it is assumed that the suction of the filter paper corresponds to that of the soil. The soil water retention curve is finally determined based on several pairs of measurements (suction-water content) on several soil samples by varying the water content from dry to saturated state on many samples.

$$
\begin{array}{ll}
\log (\psi)=5.327-0.0779 . w & \text { For } w<45.3 \% \\
\log (\psi)=2.412-0.0135 . w & \text { For } w>45.3 \%
\end{array}
$$

\subsection{SWCC results}

The water retention curves obtained for the studied material are given in figure $6 \mathrm{a}$, in the plane $\left[\log (\mathrm{s})-\mathrm{S}_{\mathrm{r}}\right]$. The different curves show a progressive desaturation of the soil with suction increases. It can be seen that the dry density increase has the effect of increasing the soil suction values. Suction values can range from $1 \mathrm{MPa}$ to $100 \mathrm{MPa}$ for a density state ranging from $75 \%$ to $87 \%$ of the maximum modified Proctor dry density.

For the adjustment of the experimental results, we used the equation of Brooks and Corey (1964) [14] which relates the degree of saturation to the suction as presented in equation (3).

$$
S_{r}(\psi)=\frac{w(\psi)}{w_{s}}=\left(\frac{\psi_{a e v}}{\psi}\right)^{\lambda}
$$

Where $w(\psi), w_{s}$ and $S_{r}$ are respectively the water content as a function of the suction $\psi$, the saturation water content and the degree of saturation. $\psi_{a e v}$ is the air entry value and $\lambda$ is a parameter related to the pore size distribution of the material and having an influence on the slope of the SWCC. Table 4 presents the results of the SWCC tests.

Table 4. Parameters of the equation of Brooks and Corey (1964) [14] according to the experimental results obtained.

\begin{tabular}{|c|c|c|c|c|}
\hline $\begin{array}{c}\text { Percentage of } \\
\text { the MMPD (\%) }\end{array}$ & $\mathbf{9 5}$ & $\mathbf{8 7}$ & $\mathbf{8 0}$ & $\mathbf{7 5}$ \\
\hline$\gamma_{d}\left(\mathrm{kN} / \mathrm{m}^{3}\right)$ & 15.7 & 14.3 & 13.2 & 12.4 \\
\hline$e$ & 0.72 & 0.88 & 1.04 & 1.18 \\
\hline$\lambda$ & 0.33 & 0.33 & 0.33 & 0.33 \\
\hline$\psi_{\text {aev }}(\mathrm{kPa})$ & 2000 & 1200 & 200 & 60 \\
\hline
\end{tabular}
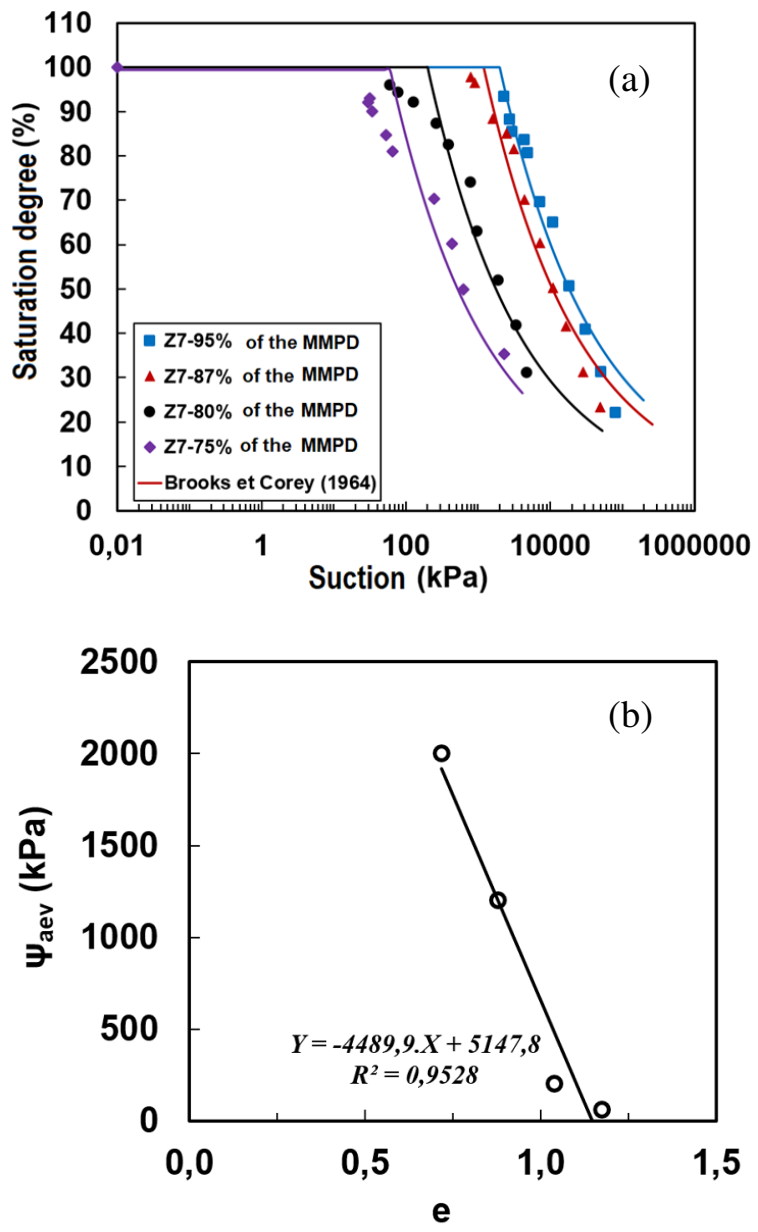

Fig. 6. (a) SWCC for different dry densities, (b) relationship between void ratio and air entry value

Figure $6 \mathrm{~b}$ shows that the air entry value $\left(\psi_{\text {aev }}\right)$ is related to the void ratio (e) according to a linear relationship given by equation (4), with the values of parameters A and B proposed in table 5.

$$
\psi_{\text {aev }}=A . e+B
$$


Table 5. Parameters A and B (in $\mathrm{kPa}$ ).

\begin{tabular}{|c|c|}
\hline A & -4489.9 \\
\hline B & 5147.8 \\
\hline
\end{tabular}

However, we note that since parameter $\mathrm{A}$ is negative, the air entry value tends to be negative if the void ratio becomes very high. For this reason we validated this relationship only for void ratio values between 0.4 and 1.146.

\subsection{Shrinkage test}

To estimate the volume variations under hydric stress of the residual pelitic soil, we subjected it to a drainage phase. We previously sieved the material at $5 \mathrm{~mm}$ and then compacted it to in-situ dry density (i.e. $12.4 \mathrm{kN} / \mathrm{m}^{3}$, or $75 \%$ of the maximum modified Proctor dry density) to make cylindrical specimens $59 \mathrm{~mm}$ in diameter and $25 \mathrm{~mm}$ thick. The different specimens were prepared at the saturation water content (i.e. $44 \%$ ).

After the specimens were prepared, we first noted their initial characteristics (wet mass, volume) and then dried them in the laboratory at $21^{\circ} \mathrm{C}$. During drying, gradual measurments of the variation in their masses and volumes until the measured variations became negligible were made.

This procedure was described by $[15,16]$ to highlight the role of matrix suction on drying-wetting paths on samples subjected to no external stress. $[15,16]$ indicated that in the case of compacted soils at the Proctor optimum, for wetting path, there is a good linearity relationship in the planes $[\log (\psi), \mathrm{e}]$ and $[\log (\psi), \mathrm{w}]$ for suctions between 0.1 and $10 \mathrm{MPa}$. They noted also that the wetting path for compacted soils at Proctor optimum can be defined by its characteristics, specifically its slope.

\subsection{Shrinkage test results}

For these tests, suction was estimated from the measured data (water content and void ratio) and the parameters of the Brooks and Corey equation [14] adjusted from the SWCC test results, equation (5).

$$
\psi=\frac{\psi_{a e v}}{S_{r}^{1 / \lambda}}
$$

In this expression, the air entry value is related to the void ratio by equation (4).

The results obtained are presented in Figure 7. Figure 7a shows the shrinkage curve of the residual pelitic soil. It should be noted that at the beginning of drying, the drainage path is linear and then changes direction after a point corresponding to the shrinkage limit, $w_{S L}(19 \%)$. Figure $7 \mathrm{~b}$ shows that in the plane $[\log (\psi)$-e], from the void ratio corresponding to the shrinkage limit, the soil no longer undergoes a large volume variation; the variation in the void ratio becomes almost linear. The decrease in the void ratio is estimated at $56 \%$ of the initial void ratio.
Figures 7d and 7e show that soil desaturation continues even after the shrinkage limit is reached.

The results of the shrinkage test show that suction corresponding to the in-situ density, at $75 \%$ of the maximum modified Proctor dry density with a void ratio of 1.18 and for water contents high than $40 \%$ is quite low. This can explain the in-situ dynamic cone resistance values obtained in the subgrade soil. (a)

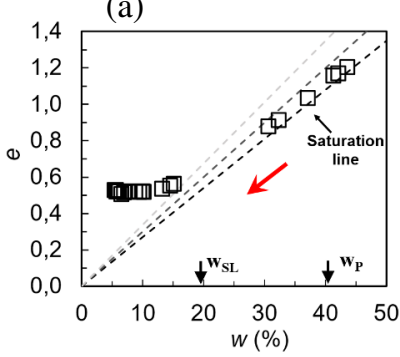

(c)
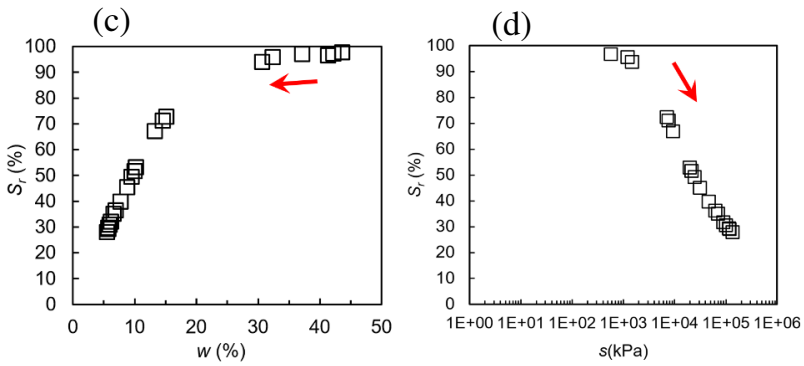

(b)

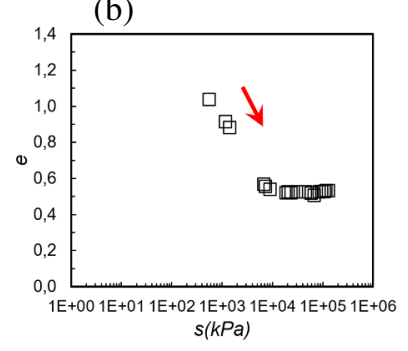

(d)

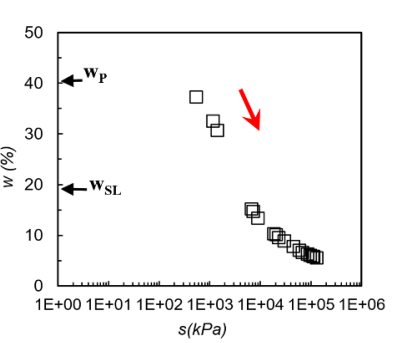

Fig. 7. Sample compacted and then dried (initial dry density $12.4 \mathrm{kN} / \mathrm{m}^{3}$, or $75 \%$ of the MMPD).

\section{Conclusion}

In this article we focused on the characterization of behaviour of pelitic soil constituting the subgrade of a part of the Trans-Gabon Railway track. On site penetrometric and geoendoscopic tests showed that the subgrade soil has a low resistance with a low variability. The SWCCs determined for different dry densities provided a linear relationship between the void ratio and the air entry value. This relationship was used to estimate suction values from the Brooks and Corey (1964) equation [14] to determine the curves describing soil volumetric behaviour. The soil can undergo shrinkage when drained and the volumetric variation associated with this phenomenon can reach $56 \%$. Soil mechanical behaviour could be very sensible to hydric variation since suction values can reach more than $10 \mathrm{MPa}$. We also saw that for high water content $(>40 \%)$ as it is the case for the natural water content on the 
studied area, soil suction can be low $(<300 \mathrm{kPa})$ which results in low subgrade soil resistance.

\section{References}

1. C. W. W. Ng and C. Zhou, in: A. Ferrari, L. Laloui (eds), Advances in Laboratory Testing and Modelling of Soils and Shales (ATMSS) (Springer, 2017).

2. D. Li and E. T. Selig, Transp. Res. Rec. 1489, 1725 (1995).

3. D. Li and E. T. Selig, J. Geotech. Eng., 122, 12, 1006-1013 (1996).

4. S. M. R. Hosseini, S. A. Naeini, and M. Hassanlourad, Int. J. Geotech. Eng., 11, 3, 225-235 (2016).

5. Z. Han and S. K. Vanapalli, Geotech. Spec. Publ., vol. GSP 256, no. 1, 2112-2121 (2015).

6. Y. Haddani, G. Saussine, M. A. Benz-Navarrete, F. Ranvier, and R. Gourvès, "Caractérisation physique et mécanique des couches d'assises ferroviaires au pandoscope ${ }^{\circledR}, " \quad$ in Symposium International GEORAIL 2017, 261-270 (2017).

7. J. C. Cripps and R. K. Taylor, Q. J. Eng. Geol., 14, 4, 325-346 (1981).

8. B. B. K. Huat, D. G. Toll, and A. Prasad, Handbook of Tropical Residual Soils Engineering, (CRC Press, 2013).

9. S. Yamasaki and M. Chigira, Disaster Mitigation of Debris Flows, Slope Failures and Landslides, 393401 (2006).

10. E. L. De Almeida, S. Teixeira, and F. Chagas, , R. Bras. Ci. Solo, 39, 5, 1344-1352 (2015).

11. H. Kim, E. Ganju, D. Tang, and M. Prezzi, Road Mater. Pavement Des., 16, 2, 358-378 (2015).

12. K.V. Bicalho, A. Gomes Correira, S. Ferreira, J. M. Fleureau, and F. A. M. Marinho, "Filter paper method of soil suction measurement", in: XIII Panamer. Confer. Soil Mech. Geotech. Eng. (2007).

13. ASTM, "Standard Test Method for Measurement of Soil Potential (Suction) Using Filter Paper (2003).

14. R. H. Brooks and A. T. Corey, "Hydraulic properties of porous media", Hydrology papers, (Colorado State University, 1964).

15. O. Coussy and J.-M. Fleureau, Mécanique des sols non saturés, (Lavoisier, 2002).

16. J.-M. Fleureau, J.-C. Verbrugge, P. J. Huergo, A. G. Correia and S. Kheirbek-Saoud, Can. Geotech. J., 39, 6, 1341-1357, (2002). 